\title{
Prevalence of antibodies to Leishmania infantum and Toxoplasma gondii in horses from the north of Portugal
}

\author{
Ana Patrícia Lopes ${ }^{1,2}$, Susana Sousa ${ }^{3}$, JP Dubey ${ }^{4}$, Ana J Ribeiro ${ }^{5}$, Ricardo Silvestre ${ }^{3}$, Mário Cotovio ${ }^{1,2}$, \\ Henk DFH Schallig ${ }^{6}$, Luís Cardoso ${ }^{1,3^{*}}$ and Anabela Cordeiro-da-Silva ${ }^{3,7}$
}

\begin{abstract}
Background: Leishmania infantum and Toxoplasma gondii are protozoa with zoonotic and economic importance. Prevalences of antibodies to these agents were assessed in 173 horses from the north of Portugal.

Findings: Antibodies to L. infantum were detected by the direct agglutination test (DAT); seven (4.0\%) horses were seropositive with DAT titres of $200(n=5), 800(n=1)$ and $\geq 1600(n=1)$. Antibodies to T. gondii were assayed by the modified agglutination test (MAT); $23(13.3 \%)$ horses were seropositive with MAT titres of $20(n=13), 40(n=5)$, $80(n=3)$ and $\geq 160(n=2)$. No statistical differences were found among equine categories of gender (female, male and gelding), age (1.5-6, 7-12 and 13-30 years), type of housing (indoors and mixed/outdoors), ability (recreation, farming and sports) and clinical status (apparently healthy and sick) for both agents.
\end{abstract}

Conclusions: Horses are exposed to and may be infected with L. infantum and T. gondii in the north of Portugal.

Keywords: Antibodies, Horses, Leishmania infantum, Portugal, Toxoplasma gondii

\section{Findings}

Protozoan parasites Leishmania spp. and Toxoplasma gondii are agents of zoonotic diseases with considerable importance worldwide [1,2]. Leishmaniosis caused by Leishmania infantum (syn. Leishmania chagasi) is endemic in the Mediterranean basin (including Portugal), the Americas, and Asia. Dogs are the main reservoir of the parasite, which is transmitted among animals and to humans by phlebotomine sand flies [3]. Infection with $L$. infantum in humans may cause severe visceral or mild cutaneous clinical outcomes, while canine leishmaniosis is a relatively frequent chronic viscerocutaneous and even fatal illness [4]. Cases of presumed autochthonous cutaneous leishmaniosis in horses have been sporadically reported from southern [5] and Central Europe [6].

\footnotetext{
* Correspondence: Icardoso@utad.pt

'Department of Veterinary Sciences, School of Agrarian and Veterinary Sciences, University of Trás-os-Montes e Alto Douro (UTAD), Vila Real, Portugal

${ }^{3}$ Parasite Disease Group, Instituto de Biologia Molecular e Celular (IBMC), Universidade do Porto, Porto, Portugal

Full list of author information is available at the end of the article
}

Toxoplasmosis can be the cause of morbidity and mortality in congenitally infected children and imunocompromised people [1]. Felids are the only recognized definitive hosts of the parasite, while a large variety of mammals, including human beings and horses, serve as intermediate hosts. The consumption of improperly cooked infected horse meat can be a risk to human health, sometimes with serious consequences [7]. Recently, public attention has been drawn to adulteration of beef with horse meat in Europe.

The present study aimed at estimating the seroprevalences of L. infantum and T. gondii in horses from the north of Portugal, since no information is available on these zoonotic agents among the regional equine population.

Between November 2008 and July 2010, blood from 173 horses living in the north of Portugal was collected from a jugular vein into EDTA tubes and plasma stored at $-25^{\circ} \mathrm{C}$ until use. Information on gender, age, type of housing and ability (Table 1 ) was obtained by filling in a questionnaire. The average age was 9.3 years (standard deviation: 5.8 years). Based on physical examination and clinical history, horses were considered as sick if they 
Table 1 Seropositivity among horses from the north of Portugal to Leishmania infantum and Toxoplasma gondii by gender, age group, type of housing, ability and clinical status

\begin{tabular}{|c|c|c|c|c|c|c|}
\hline & Animals tested (n) & Relative & L. ir & positive & T. $g$ & ositive \\
\hline & & & (n) & (\%) & (n) & (\%) \\
\hline Gender & & & & & & \\
\hline Female & 78 & 45.1 & 3 & 3.8 & 11 & 14.1 \\
\hline Male & 30 & 17.3 & 2 & 6.7 & 1 & 3.3 \\
\hline Gelding & 65 & 37.6 & 2 & 3.1 & 11 & 16.9 \\
\hline Age (years) & & & & & & \\
\hline $1.5-6$ & 48 & 27.7 & 3 & 6.3 & 5 & 10.4 \\
\hline $7-612$ & 76 & 43.9 & 1 & 1.3 & 8 & 10.5 \\
\hline $13-630$ & 49 & 28.3 & 3 & 6.1 & 10 & 20.4 \\
\hline Housing & & & & & & \\
\hline Indoors & 73 & 42.2 & 3 & 4.1 & 6 & 8.2 \\
\hline Mixed/outdoors & 99 & 57.2 & 4 & 4.0 & 17 & 17.2 \\
\hline Not determined & 1 & 0.6 & 0 & 0.0 & 0 & 0.0 \\
\hline Ability & & & & & & \\
\hline Recreation & 109 & 63.0 & 7 & 6.4 & 14 & 12.8 \\
\hline Farming & 30 & 17.3 & 0 & 0.0 & 4 & 13.3 \\
\hline Sports & 30 & 17.3 & 0 & 0.0 & 5 & 16.7 \\
\hline Not determined & 4 & 2.3 & 0 & 0.0 & 0 & 0.0 \\
\hline Clinical status & & & & & & \\
\hline Apparently healthy & 148 & 85.5 & 5 & 3.4 & 21 & 14.2 \\
\hline Sick & 14 & 8.1 & 2 & 14.3 & 2 & 14.3 \\
\hline Not determined & 11 & 6.4 & 0 & 0.0 & 0 & 0.0 \\
\hline Total & 173 & 100 & 7 & 4.0 & 23 & 13.3 \\
\hline
\end{tabular}

had fever, anorexia and/or intolerance to exercise. Those animals with no detectable clinical signs were regarded as apparently healthy (Table 1). This study was approved by the University of Trás-os-Montes e Alto Douro Veterinary Teaching Hospital ethical committee as complying with the Portuguese legislation for the protection of animals (Law no. 92/1995, 12 September).

The direct agglutination test (DAT) for titration of immunoglobulin G (IgG) antibodies specific to Leishmania followed the general procedures described by Schallig et al. [8], using a standard freeze-dried antigen at a concentration of $5 \times 10^{7}$ promastigotes $/ \mathrm{ml}$ (KIT Biomedical Research, Amsterdam, The Netherlands). Twofold dilution series ranging from 1:25 to 1:1600 were tested. Results obtained with the DAT are expressed as an antibody titre, i.e. the reciprocal of the highest dilution at which agglutination (large diffuse blue mats) is still clearly visible after $18 \mathrm{~h}$ incubation at room temperature. Plasma from a horse from the north of Portugal with cutaneous leishmaniosis (J. Elias and col., personal communication) and a DAT titre of 200 was used as positive control. Plasma from another horse (DAT titre $<25$ ) that lived in a non-endemic region was used as negative control. To maximize specificity and sensitivity of the DAT, a cut-off titre of 200 was chosen for seropositivity.

The plasma samples were tested for IgG antibodies to $T$. gondii with a modified agglutination test (MAT) commercial kit (Toxo-Screen DA ${ }^{\circledR}$, bioMérieux, Lyon, France) following the manufacturer's instructions. Sera were analysed at the dilutions of 1:20, 1:40, 1:80 and 1:160. Positive and negative controls supplied with the kit were included in each plate. MAT positive results had visible agglutination (at least one half of the well's diameter) after $5-18 \mathrm{~h}$ of incubation at room temperature. A cut-off titre of 20 (2 IU/ $\mathrm{ml}$ in relation to a WHO international reference serum) was chosen to maximize both sensitivity and specificity of the test $[9,10]$.

Chi-square or Fisher's exact tests were used to compare percentages, including positivity levels among categories of the same independent variables (i.e. gender, age, type of housing, ability and clinical status) and total prevalences of antibodies to each one of the two agents. Exact binomial test established confidence intervals (CI) for the totals, with a 95\% confidence level. Analyses were carried out using StatLib and SPSS 11.5 software for 
Windows, with a probability $(p)$ value $<0.05$ regarded as statistically significant [11].

Table 1 summarizes results. The seven (4.0\%; 95\% CI: 1.6-8.2) horses seropositive to L. infantum had titres of $200(\mathrm{n}=5), 800(\mathrm{n}=1)$ and $\geq 1600(\mathrm{n}=1)$. The 166 horses seronegative to L. infantum had titres of $<25(\mathrm{n}=156), 25$ $(\mathrm{n}=2)$ and $50(\mathrm{n}=8)$. The 23 (13.3\%; 95\% CI: 8.6-19.3) horses seropositive to T. gondii had titres of $20(\mathrm{n}=13)$, $40(\mathrm{n}=5), 80(\mathrm{n}=3)$ and $\geq 160(\mathrm{n}=2)$. No horse was simultaneously seropositive to L. infantum and T. gondii.

This is the first epidemiological investigation on equine Leishmania and T. gondii infections in the north of Portugal, a region where both agents have previously been found to be endemic in other hosts species $[12,13]$. A higher level of exposure to T. gondii in comparison with $L$. infantum has been revealed in horses from northern Portugal, but gender, age, type of housing, ability and clinical status had no significant influence on the seropositivity to both parasites. The fact that no horse was simultaneously seropositive to $L$. infantum and $T$. gondii is a good indicator of the high specificity of the direct agglutination tests under use (i.e. the DAT and MAT).

Also by using the DAT, seroprevalences of Leishmania in dogs from the north of Portugal have been shown to range from less than 5\% [14] to approximately 20\% [12]. In domestic cats from this region prevalence found by means of the same serological test was $1.9 \%$ [15]. This is the first report of the DAT being used to investigate Leishmania infection in horses in Europe.

To the best of our knowledge, in Portugal only two clinical cases of equine cutaneous leishmaniosis have been reported: one from the north (J. Elias and col., personal communication) and the other one from the south-central region of Lisbon [16]. As previously observed in dogs, cats and humans, in areas of endemicity, the prevalence of subclinical Leishmania infection in horses is considerably higher than that of the disease $[2,15,17]$.

In northern Portugal, out of 57 female Phlebotomus ariasi and Phlebotomus perniciosus, 38.6\% were found to have fed on humans, $19.3 \%$ on dogs, $12.3 \%$ on chicken and $29.8 \%$ on other species, but no sand flies were detected with equine blood [18]. Nevertheless, in Spain $P$. perniciosus has been shown to feed on horses [19], a fact that does not exclude equines from taking part in the epidemiology of $L$. infantum.

Worldwide seroprevalences of $T$. gondii in horses were summarized by Dubey and Beattie [20] and Dubey [1]. In general, seroprevalence in horses is lower than in other livestock species and prevalences were higher in domestic than in wild horses [1]. The MAT titre that should be considered specific for the detection of antibodies to $T$. gondii in horses is unknown because only a few attempts have been made to isolate viable $T$. gondii from naturally exposed horses. Judging from results obtained with other species, a MAT titer of 20 is considered specific for the detection of antibodies to $T$. gondii. In the present study, 10 of the 23 seropositive horses had a titre of 40 or higher. Viable T. gondii was isolated from horses even with a very low titer of 4 in the Sabin Feldman dye test and horses experimentally infected with $T$. gondii oocysts do develop high MAT titres [9].

Horses are considered clinically resistant to toxoplasmosis and there are no confirmed cases of clinical toxoplasmosis in these animals [1]. The results of the present study indicate that horses in the north of Portugal are exposed to T. gondii and so their tissues might harbour parasitic cysts. The voluntary consumption of horse meat by people is not a common habit in Portugal, but the risk of $T$. gondii transmission from horses to humans should not be neglected due to the recent contamination of beef with horse meat noticed in Europe. Infections with $T$. gondii are common in food animals and humans in northern Portugal $[13,21]$.

\section{Conclusions}

In conclusion, horses are commonly exposed to and may be infected with $L$. infantum and T. gondii in areas where these zoonotic parasites are endemic, such as the north of Portugal. The degree of involvement of horses in the specific transmission of these agents to other hosts including humans is yet to be defined at the local level. However, in any case should equine infections with $L$. infantum or T. gondii be underestimated, respectively, as a potential cause of disease for horses themselves and as a risk to public health.

\section{Competing interests}

The authors declare that they have no competing interests.

\section{Authors' contributions}

APL participated in serological testing and data analysis and drafted the manuscript; SS participated in serological testing and data analysis; JPD, RS, HDFHS and ACdS provided conceptual advice and reviewed the manuscript; AJR and MC collected samples and clinical data; LC participated in data analysis, helped to draft and revised the manuscript. All authors read and approved the final manuscript.

\section{Acknowledgements}

The authors would like to thank Dr. José M. Maia for collecting and characterizing samples from horses. This work was funded by FEDER funds through the Operational Competitiveness Programme - COMPETE and by National funds through FCT - Fundação para a Ciência e a Tecnologia under the project FCOMP-01-0124-FEDER-014658 (PTDC/CVT/110732/2009). RS was supported by Programa Ciência, financed by Programa Operacional Potencial Humano - Quadro de Referência Estratégica Nacional - Tipologia 4.2 Promocão do Emprego Científico, cofunded by Fundo Social Europeu and national funding from the Ministry of Science, Technology and Higher Education.

\section{Author details}

${ }^{1}$ Department of Veterinary Sciences, School of Agrarian and Veterinary Sciences, University of Trás-os-Montes e Alto Douro (UTAD), Vila Real, Portugal. ${ }^{2}$ Animal and Veterinary Research Centre, UTAD, Vila Real, Portugal. 
${ }^{3}$ Parasite Disease Group, Instituto de Biologia Molecular e Celular (IBMC) Universidade do Porto, Porto, Portugal. ${ }^{4}$ Animal Parasitic Diseases Laboratory, Beltsville Agricultural Research Center, Agricultural Research Service, United States Department of Agriculture, Beltsville, MD, USA. ${ }^{5}$ Veterinary Hospital, UTAD, Vila Real, Portugal. ${ }^{6}$ Department of Parasitology, Koninklijk Instituut voor de Tropen (KIT), Royal Tropical Institute, Amsterdam, The Netherlands. ${ }^{7}$ Departamento de Ciências Biológicas, Faculdade de Farmácia, UP, Porto, Portugal.

Received: 7 May 2013 Accepted: 13 June 2013

Published: 17 June 2013

\section{References}

1. Dubey JP: Toxoplasmosis of Animals and Humans. 2nd edition. Boca Raton: CRC Press; 2010

2. WHO: Control of the Leishmaniases, WHO Technical Report Series 949. Geneva: World Health Organization; 2010.

3. Palatnik-de-Sousa CB, Day MJ: One Health: The global challenge of epidemic and endemic leishmaniasis. Parasit Vectors 2011, 4:197.

4. Solano-Gallego L, Miró G, Koutinas A, Cardoso L, Pennisi MG, Ferrer L, Bourdeau P, Oliva G, Baneth G: LeishVet guidelines for the practical management of canine leishmaniosis. Parasit Vectors 2011, 4:86.

5. Solano-Gallego L, Fernández-Bellon H, Serra R, Gállego M, Ramis $A$, Fondevila D, Ferrer L: Cutaneous leishmaniosis in three horses in Spain. Equine Vet J 2003, 35:320-323.

6. Müller N, Welle M, Lobsiger L, Stoffel MH, Boghenbor KK, Hilbe M, Gottstein B, Frey CF, Geyer C, Von Bomhard W: Occurrence of Leishmania sp. in cutaneous lesions of horses in Central Europe. Vet Parasitol 2009, 166:346-351.

7. Pomares C, Aizenberg D, Bornard L, Bernardin G, Hasseine L, Dardé M-L, Marty P: Toxoplasmosis and horse meat, France. Emerg Infect Dis 2011, 17:1327-1328.

8. Schallig HDFH, Schoone GJ, Beijer EGM, Kroon CCM, Hommers M, Özbel Y, Özensoy S, da Silva ES, Cardoso LM, da Silva ED: Development of a fast agglutination screening test (FAST) for the detection of anti-Leishmania antibodies in dogs. Vet Parasitol 2002, 109:1-8.

9. Dubey JP, Desmonts G: Serological responses of equids fed Toxoplasma gondii oocysts. Equine Vet J 1987, 19:337-339.

10. Boughattas S, Bergaoui R, Essid R, Aoun K, Bouratbine A: Seroprevalence of Toxoplasma gondii infection among horses in Tunisia. Parasit Vectors 2011, 4:218.

11. Petrie A, Watson P: Statistics for Veterinary and Animal Science. 2nd edition. Oxford: Blackwell Publishing; 2006.

12. Sousa S, Lopes AP, Cardoso L, Silvestre R, Schallig H, Reed SG, Cordeiro da Silva A: Seroepidemiological survey of Leishmania infantum infection in dogs from northeastern Portugal. Acta Trop 2011, 120:82-87.

13. Lopes AP, Dubey JP, Neto F, Rodrigues A, Martins T, Rodrigues M, Cardoso L: Seroprevalence of Toxoplasma gondii infection in cattle, sheep, goats and pigs from the North of Portugal for human consumption. Vet Parasitol 2013, 193:266-269.

14. Cardoso L, Mendão C, Madeira de Carvalho L: Prevalence of Dirofilaria immitis, Ehrlichia canis, Borrelia burgdorferi sensu lato, Anaplasma spp. and Leishmania infantum in apparently healthy and CVBD-suspect dogs in Portugal - a national serological study. Parasit Vectors 2012, 5:62.

15. Cardoso L, Lopes AP, Sherry K, Schallig H, Solano-Gallego L: Low seroprevalence of Leishmania infantum infection in cats from northern Portugal based on DAT and ELISA. Vet Parasitol 2010, 174:37-42.

16. Rolão N, Martins MJ, João $A$, Campino L: Equine infection with Leishmania in Portugal. Parasite 2005, 12:183-186.

17. Fernández-Bellon H, Solano-Gallego L, Bardagí M, Alberola J, Ramis A, Ferrer $L$ : Immune response to Leishmania infantum in healthy horses in Spain. Vet Parasitol 2006, 135:181-185.

18. Alves-Pires C, Novo MT, Sousa CA: Os flebótomos de Portugal. VII Preferências hemáticas dos flebótomos (Diptera, Psychodidae) da região do Alto Douro. Bol Soc Port Entomol 1992, 3:607-613.

19. De Colmenares M, Portús M, Botet J, Dobaño C, Gállego M, Wolff M, Seguí G: Identification of blood meals of Phlebotomus perniciosus (Diptera:
Psychodidae) in Spain by a competitive enzyme-linked immunosorbent assay biotin/avidin method. J Med Entomol 1995, 32:229-233.

20. Dubey JP, Beattie CP: Toxoplasmosis of Animals and Man. Boca Raton: CRC Press; 1988.

21. Lopes AP, Dubey JP, Moutinho O, Gargaté MJ, Vilares A, Rodrigues M, Cardoso L: Seroepidemiology of Toxoplasma gondii infection in women from the North of Portugal in their childbearing years. Epidemiol Infect 2012, 31:1-6.

doi:10.1186/1756-3305-6-178

Cite this article as: Lopes et al:: Prevalence of antibodies to Leishmania infantum and Toxoplasma gondii in horses from the north of Portugal.

Parasites \& Vectors 2013 6:178.

\section{Submit your next manuscript to BioMed Central and take full advantage of:}

- Convenient online submission

- Thorough peer review

- No space constraints or color figure charges

- Immediate publication on acceptance

- Inclusion in PubMed, CAS, Scopus and Google Scholar

- Research which is freely available for redistribution

Submit your manuscript at www.biomedcentral.com/submit
( Biomed Central 